University of Nebraska - Lincoln

DigitalCommons@University of Nebraska - Lincoln

Ecophysiological Determinants of Sexual Size Dimorphism: Integrating Growth Trajectories, Environmental Conditions, and Metabolic Rates

\author{
Marie-Claire Chelini \\ University of California, Merced, mcchelini@gmail.com \\ John P. DeLong \\ University of Nebraska - Lincoln, jpdelong@unl.edu \\ Eileen A. Hebets \\ University of Nebraska - Lincoln, ehebets2@unl.edu
}

Follow this and additional works at: https://digitalcommons.unl.edu/bioscihebets

Part of the Animal Sciences Commons, Behavior and Ethology Commons, Biology Commons, Entomology Commons, and the Genetics and Genomics Commons

Chelini, Marie-Claire; DeLong, John P.; and Hebets, Eileen A., "Ecophysiological Determinants of Sexual Size Dimorphism: Integrating Growth Trajectories, Environmental Conditions, and Metabolic Rates" (2019). Eileen Hebets Publications. 86.

https://digitalcommons.unl.edu/bioscihebets/86

This Article is brought to you for free and open access by the Papers in the Biological Sciences at DigitalCommons@University of Nebraska - Lincoln. It has been accepted for inclusion in Eileen Hebets Publications by an authorized administrator of DigitalCommons@University of Nebraska - Lincoln. 
Chelini, DeLong, and Hebets in Oecologia (2019) 191: 61-71. doi: 10.1007/s0044 2-019-04488 -9.

Copyright 2019, Springer-Verlag. Used by permission.

\title{
Ecophysiological Determinants of Sexual Size Dimorphism: Integrating Growth Trajectories, Environmental Conditions, and Metabolic Rates
}

\author{
Marie-Claire Chelini, John P. Delong, and Eileen A. Hebets
}

\begin{abstract}
Sexual size dimorphism (SSD) often results in dramatic differences in body size between females and males. Despite its ecological importance, little is known about the relationship between developmental, physiological, and energetic mechanisms underlying SSD. We take an integrative approach to understand the relationship between developmental trajectories, metabolism, and environmental conditions resulting in extreme female-biased SSD in the crab spider Mecaphesa celer (Thomisidae). We tested for sexual differences in growth trajectories, as well as in the energetics of growth, hypothesizing that female $M$. celer have lower metabolic rates than males or higher energy assimilation. We also hypothesized that the environment in which spiderlings develop influences the degree of SSD of a population. We tracked growth and resting metabolic rates of female and male spiderlings throughout their ontogeny and quantified the adult size of individuals raised in a combination of two diet and two temperature treatments. We show that M. celer's SSD results from differences in the shape of female and male growth trajectories. While female and male resting metabolic rates did not differ, diet, temperature, and their interaction influenced body size through an interactive effect with sex, with females being more sensitive to the environment than males. We demonstrate that the shape of the growth curve is an important but often overlooked determinant of SSD and that females may achieve larger sizes through a combination of high food ingestion and low activity levels. Our results highlight the need for new models of SSD based on ontogeny, ecology, and behavior.
\end{abstract}

Keywords Growth trajectories, Ontogeny, SSD, Temperature-size rule, Thomisidae

\section{Introduction}

Body size is one of the most important traits of any organism, as it influences processes ranging from intracellular reactions to community structure and dynamics (Savage et al. 2004; Gillooly et al. 2005; Brose et al. 2006; Riede et al. 2011; DeLong et al. 2015). In species with sexual size dimorphism (SSD), body size and all processes associated with it can vary widely between the sexes. Fitness benefits associated with different body sizes in females and males have been studied in depth in a wide range of taxa, from mammals to

M-CC: School of Natural Sciences, University of California, Merced, Merced, California, USA, mcchelini@gmail.com JPD, EAH: School of Biological Sciences, University of Nebraska-Lincoln, Lincoln, Nebraska, USA insects (Blanckenhorn 2000, 2005; Preziosi and Fairbairn 2000; Cox and Calsbeek 2009). Understanding the evolution of SSD, however, depends on determining how these dimorphic organisms reach drastically different sizes at adulthood despite sharing a similar physiology and autosomal genomes (Fairbairn 1997; Badyaev 2002a; Teder 2014; Chou et al. 2016).

The proximate mechanisms of SSD - i.e. its developmental, energetic, behavioral, and physiological basis - have typically been studied from one of two primary perspectives: (1) comparing developmental growth trajectories (i.e. ontogeny) of females and males or (2) focusing on individual-level energy budgets, comparing foraging rates and energetic expenditure of females and males. These two perspectives are, however, fundamentally interrelated: If growth trajectories differ, how does the larger sex fuel its faster or longer growth? Rather than solving the proximate

Received March 25, 2019; accepted August 13, 2019; published online August 20, 2019; uploaded to the UNL institutional repository January 2021. 
basis of SSD, focusing on a single one of these perspectives in isolation leads to inevitably partial and biased, if not possibly wrong, answers.

From an ontogenetic standpoint, SSD is achieved through differences in growth trajectories: sexes may be born at different sizes, one sex may grow for longer than the other, or one sex may grow faster than the other (Leigh and Shea 1996; Badyaev 2002a; Blanckenhorn et al. 2007; Stillwell et al. 2010; Teder 2014). Differences in egg size or size at birth are extremely rare in arthropods (Stillwell et al. 2010; Teder 2014; but see Budrienè et al. 2013) but have been observed in birds (Weatherhead and Teather 1994) and mammals (Ono and Boness 1996; Smith and Leigh 1998). The difference in size at birth is, however, seldom proportional to the degree of SSD reached at adulthood (Weatherhead and Teather 1994; Badyaev 2002a). In contrast to differences in size at birth, differences in growth duration, growth rate, and a combination of both are all common in sexually size dimorphic mammals (Smith and Leigh 1998; Badyaev 2002a; Garel et al. 2006; O'Mara et al. 2012), reptiles (Shine 1994) and a vast number of arthropods (Blanckenhorn et al. 2007; Stillwell and Davidowitz 2010; Teder 2014). Truly understanding the growth trajectory underlying SSD requires, however, a detailed analysis of the entire development of both sexes. Indeed, quantifying the relationship between size at adulthood and duration of development cannot uncover periods of sex-specific increased growth. Such life-long analyses of growth patterns across sexes are scarce, presumably due to the logistical difficulties involved in following daily the growth of large numbers of individuals of both sexes for extensive periods of time (but see Vendl et al. 2016, 2018; Rohner et al. 2017, 2018).

If SSD results from differences in the growth trajectory of females and males, we might expect that the two sexes will also differ in their allocation of energy to growth and maintenance. Indeed, life history theory predicts energetic trade-offs between growth, maintenance, and reproduction (Stearns 1976, 1989). The energy available for growth depends on an individual's energy intake (foraging) and on the energy spent maintaining its existing tissues (i.e. its resting metabolic rate) and fueling activity (Hou et al. 2008; Dmitriew 2011). As such, in species with marked degrees of SSD, the larger sex may achieve its faster/longer growth by reducing its expenditure and using the savings to further growth and/or by increasing its food energy intake (Shine 1989; Holtby and Healey 1990; Ono and Boness 1996; Isaac 2005; Mikolajewski et al. 2005; Fuselier et al. 2007; Rennie et al. 2008). In other words, in species with SSD driven by differences in growth trajectories, we expect the sexes to also differ in a couple of possible ways: (1) the larger sex has a lower overall energetic expenditure than the smaller sex and/or, (2) the larger sex has a higher foraging rate than the smaller sex.

Finally, in addition to looking at the interrelatedness of growth trajectories and energetics, it is important to also take into account the environmental context in which organisms are growing when determining the proximate basis of SSD (Teder and Tammaru 2005). Indeed, temperature and seasonality may greatly influence growth rate, development time, and resting metabolic rates within a species. Differences in seasonal timing or geographic location may lead to variation in the growth trajectory and metabolism of each sex and, consequently, to variation in a species' degree of SSD (Badyaev 2002b; Stillwell and Davidowitz 2010; Auer et al. 2015; Rohner et al. 2018). In addition, as temperature influences metabolic rates and diet influences the amount of energy an individual has to allocate to both growth and tissue maintenance, understanding the interactive effect of both temperature and diet on female and male adult sizes sheds light into the metabolic basis of SSD.

In this study, we explore the proximate mechanisms of SSD by quantifying changes in growth trajectories and metabolic rates among males and females of the extremely sexually dimorphic crab spider Mecaphesa celer. We also assess the effects of varying regimes of diet and temperature on their size at adulthood. Specifically, we (1) test for sexual differences in developmental time, growth rate, and the shape of growth trajectories of each instar of females and males to reveal the detailed ontogeny of SSD; (2) determine how females and males differ in the energetics of their growth, hypothesizing that female $M$. celer have a lower metabolic rate than males - i.e., they devote less energy to their tissue maintenance, saving more energy to growth. Alternatively, (3) we hypothesize that female and male $M$. celer differ in their assimilation of energy, with females having a higher food intake than males, in which case we predict that food restriction has a stronger effect on females than males. Finally, (4) we test the hypothesis that the environment in which individuals grow will influence the population-level degree of SSD by raising spiderlings in two different temperature treatments.

\section{Material and Methods}

\section{Study system}

Spiders offer an ideal system with which to study the mechanisms underlying size differences between females and males as extreme degrees of SSD, mostly female biased, have evolved multiple times within the group (Scharff and Coddington 1997; Hormiga et al. 2000; Legrand and Morse 2000). Here, we use the crab spider Mecaphesa celer (Hentz 1847) as a model system 
to understand the proximate mechanisms of SSD. Crab spiders (family Thomisidae) comprise some of the most extremely dimorphic spider species (Foellmer and Moya-Larano 2007). Female M. celer are 1.3-2 times the body size of males (measured either as cephalothorax width or total body length), but often weigh more than 10 times the average male mass. Several crab spider species, including $M$. celer, are protandric, meaning that males mature earlier than females $(\mathrm{Mu}-$ niappan and Chada 1970; Dodson and Beck 1993; Morse 2013; Chelini and Hebets 2017). The degree of SSD reached at adulthood is not, however, proportional to the observed differences in growth lengthfemales double in size in their last three instars, but mature only a few days after males (Muniappan and Chada 1970; Chelini and Hebets 2017). When and how SSD arises remain unanswered questions in such extremely dimorphic organisms, requiring a thorough analysis of the entire ontogeny of females and males.

\section{Growth trajectories}

To test the hypothesis that differences in growth trajectories underlie SSD in M. celer, we followed the growth of $250 \mathrm{M}$. celer spiderlings beginning at their second instar (first-instar spiderlings are extremely small and fragile, and remain aggregated around the egg sac until their first molt). These spiderlings were born in the laboratory between September and October 2014. They were the offspring of 48 females collected in Lincoln, Nebraska, USA in May 2014 and mated in the laboratory in August 2014. We randomly selected 5-10 spiderlings from each clutch and housed them in individual $4 \times 4 \times 6 \mathrm{~cm}$ acrylic boxes, with ad libitum water, and small pieces of netting for perching, in a room at $26^{\circ} \mathrm{C}$ and $60 \%$ relative humidity, under a $14: 10$ light:dark cycle. We checked all spiderlings for molts three times a week. After each molt, we photographed each spiderling with a Spot Flex® digital camera (Model $15.264 \mathrm{MP}$, Diagnostic Instruments, Inc.) mounted on a Leica ${ }^{\circledR}$ DM 4000 B Microscope. We fed all individuals twice a week with flightless Drosophila melanogaster in quantities corresponding to each spiderling's age: third instar spiderlings were fed three $D$. melanogaster, fourth instar spiderlings were fed four $D$. melanogaster, etc. (as a reference, third instar M. celer spiderlings are approximately twice the size of one $D$. melanogaster). This food regime allowed us to progressively increase how much food was available to each spiderling as they aged, while being kept constant across cohorts of spiderlings of the same instar and of both sexes. We used all individuals that successfully reached adulthood ( $N=43$ females and 35 males) for size and growth quantifications. As spiderling sex can only be identified at their fifth instar, our sample size was limited by the high mortality rates of early instar spiderlings whose sex was unknown.
We measured the cephalothorax width of each spiderling at each of their developmental instars from the photographs taken after their molts with ImageJ (Rasband 1997-2012). Cephalothorax width is the most recommended proxy for body size in spiders, as it remains fixed between molts and after sexual maturation and does not change with the physiological state of the spider (Prenter et al. 1995; Foellmer and Moya-Larano 2007; Foelix 2011). Linear measurements of body size, such as cephalothorax width, are nonetheless strongly correlated to mass in M. celer (Muniappan and Chada 1970, see also Online Resource 1 for a graphical comparison of mass vs. cephalothorax width change with spiderling age). We calculated spiderling age in days after birth and kept track of the date ( \pm 2 days) and number of their molts, which allowed us to determine the average length, in days and in instars, of each individual's development.

We tested for differences in female and male growth trajectories using two Gamma Generalized Linear Mixed Models (GLMMs) with a log link. In one model, we used the size (cephalothorax width) of each spiderling at each instar as the response variable, instar and sex as predictor variables, and the family ID/spiderling ID as a random effect. In a second model, we replaced the instar by their age in days. Gamma distributions were more appropriate than the linear distributions for our growth trajectory models as spiderling sizes were not normally distributed, but right skewed and heteroskedastic (Bolker et al. 2009). We ran these analyses in R v3.01, using the function glmer from the package lme4 (R Core Team 2014; Bates et al. 2015).

\section{Energetics of growth: metabolic rate measurements}

To test the hypothesis that females have a lower energetic expenditure at rest than males throughout their ontogeny, we measured the oxygen consumption rate of 146 of the spiderlings described above using an OXY-10 micro fluorescent oxygen sensor (PreSens, Regensburg, Germany). Prior to each measurement, we calibrated our oxygen sensors to $0 \%$ and $100 \% \mathrm{O}_{2}$ concentrations using vials of pure $\mathrm{N}_{2}$ and pure $\mathrm{O}_{2}$, respectively. To ensure that oxygen consumption measurements were for resting spiders, we placed each spiderling at the bottom of a $0.5 \mathrm{ml}$ Eppendorf $₫$ microcentrifuge tube and held them in place by a circular $2.5 \mathrm{~mm}$ diameter piece of netting (allowing oxygen flow but reducing spiderling movement). We then placed these microcentrifuge tubes in a thermocycler at $26{ }^{\circ} \mathrm{C}$, where spiderlings acclimated for $30 \mathrm{~min}$ before we started recording their oxygen consumption. The oxygen sensors were carefully inserted through a small hole in the cap of the Eppendorf tube, which was subsequently sealed. We checked that these tubes did not leak oxygen by placing oxygen sensors in empty tubes and verifying that the oxygen levels inside the tubes 
remained constant in the absence of a spiderling. We recorded spiderling oxygen consumption for periods of approximately $50 \mathrm{~min}$ (post-acclimation). We recorded oxygen consumption for a relatively long period of time to ensure that we would have an accurate estimate of the smaller spiderlings' metabolic rate. We then kept this recording length across all developmental instars for consistency's sake.

We calculated the metabolic rate of each spiderling as the slope of the linear regression between mass of oxygen inside the Eppendorf ${ }^{\circledR}$ tubes against time $\left(\mathrm{mg} \mathrm{O}_{2} / \mathrm{min}\right)$. To avoid including periods of spiderling stress, movement, and for consistency across measurement, we used only the shallowest segment of each spiderling's oxygen consumption slope for our estimate of resting metabolic rate. To avoid potential biases due to stress, we used the longest possible shallow segments, which varied between 20 and $45 \mathrm{~min}$. This makes our measurements of respiration rates conservative. Spiderlings typically settled on the side of the vials within minutes and moved very little afterward. To avoid quantifying the metabolic costs of digestion and molting, we controlled the timing of our measurements: we measured metabolic rates 2 days after a feeding day and between 1 and 3 weeks following their previous molt (instars vary in length from five to 80 days - Muniappan and Chada 1970). We randomly selected 10-20 individuals of each sex to be tested at each instar, with no individual being used more than once.

We weighed each spiderling to the nearest $0.1 \mathrm{mg}$ immediately after measuring their metabolic rates using an Ohaus ${ }^{\circledR}$ precision scale. Data on oxygen consumption rate and mass were log transformed to linearize the relationship between metabolic rates and size/mass. We used a linear mixed model (LMM) to determine the relationship between resting metabolic rate and each sex's mass, using the natural log of the resting metabolic rate as our response variable, sex, natural log of mass, and their interaction as predictor variables, and spiderling family as a random effect. We then conducted a likelihood ratio test between this full model, a model with log of mass as the sole predictor variable, and a null model. We ran these analyses using the function lmer from R's package lme4 and the function anova (R Core Team 2014; Bates et al. 2015).

Table 1. Summary of the diet and temperature treatments used to test the effects of the environment on the sexual size dimorphism of Mecaphesa celer

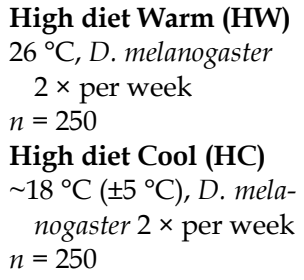

High diet Warm (HW)

${ }^{\circ} \mathrm{C}, \mathrm{D}$. melanogaster $n=250$

High diet Cool (HC)

nogaster $2 \times$ per week

$n=250$

\section{Environmental effects on SSD: diet and temperature manipulation}

To determine the effects of diet and temperature on the degree of SSD of M. celer, we subjected 1000 spiderlings to four treatments in a $2 \times 2$ factorial design involving two diet treatments (High diet vs. Low diet) and two temperature treatments (Warm vs. Cool-Table 1). All spiderlings were born in the laboratory, resulting from the same pairings described in Growth trajectories (above). Siblings were equally distributed among all treatments. The Warm treatment was identical to the environmental conditions described above (see Growth trajectories). Spiderlings from the Cool treatment were reared at temperatures averaging 18 ${ }^{\circ} \mathrm{C}$, with $\pm 5{ }^{\circ} \mathrm{C}$ fluctuations in temperature. We aimed at rearing the spiderlings in the Cool treatment at $18^{\circ} \mathrm{C}$ through their entire development, but construction in the building and issues with the heating system made it impossible for us to keep this temperature constant. As such, the experiment began with spiderlings being born in a room at $26^{\circ} \mathrm{C}$ (October), being moved to a room at $18{ }^{\circ} \mathrm{C}$ (November-December), which was subsequently cooled down to $13^{\circ} \mathrm{C}$ (January-April), then warmed up again to $16^{\circ} \mathrm{C}$ (May-June), $18^{\circ} \mathrm{C}$ (July-August), and finally to $20^{\circ} \mathrm{C}$, with mild oscillations in temperature $\left( \pm 5^{\circ} \mathrm{C}\right)$ occurring during each of these "seasons" and lasting from 1 to 3 days. We used a 14:10 light:dark cycle for all treatments. High diet spiderlings were fed with flightless D. melanogaster according to the schedule described in Growth trajectories, in quantities corresponding to each spiderling age, twice a week. Low diet spiderlings were fed the same diet, but only once a week. The spiderlings used in our analyses of Growth trajectories and Energetics of growth were the same as those of our High diet-Warm treatment. Sexually mature spiders (recognizable by developed pedipalp embolus in males and open genital operculum in females) were then photographed and measured following the same methods used for spiderlings (see Growth trajectories for details).

We tested for an effect of diet and temperature on the degree of SSD in $M$. celer with a linear model (LM), with diet, temperature, sex, and their interaction as predictor variables of the size (cephalothorax width) at adulthood. We ran these analyses using the function $\mathrm{lm}$ from R's package lme4 (R Core Team 2014; Bates et al. 2015).

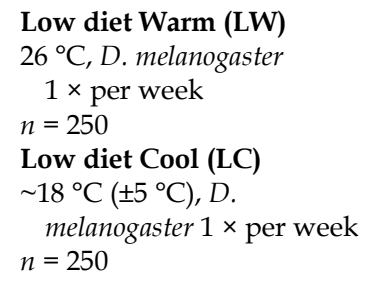



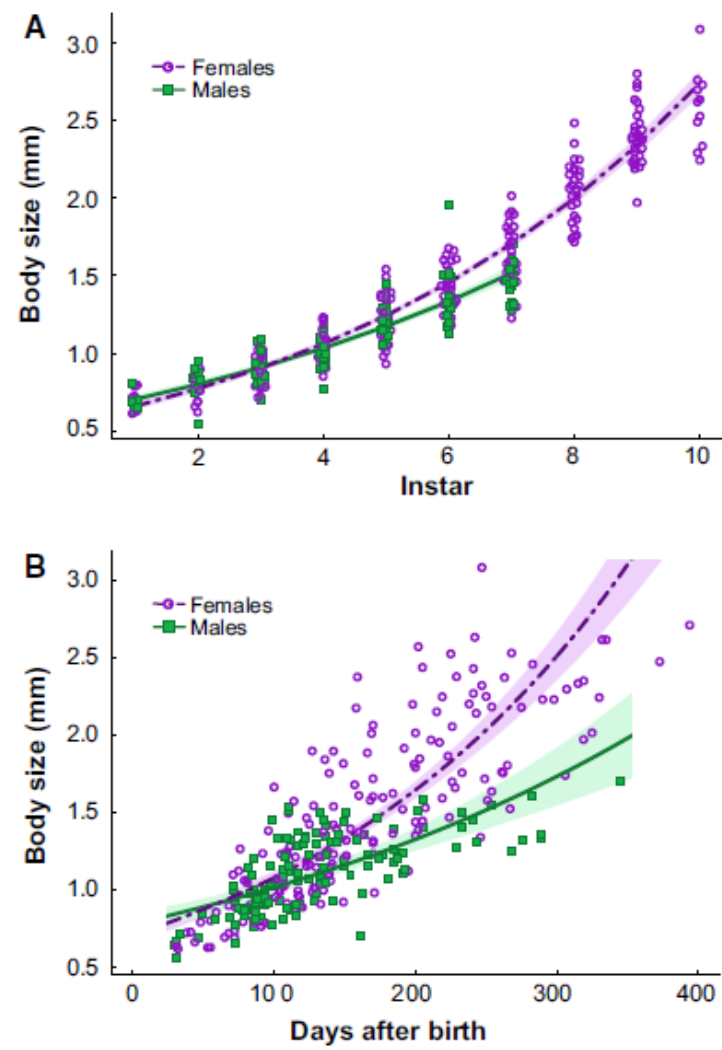

Figure 1. Growth trajectories of female and male Mecaphesa celer. a Body size (cephalothorax width) per instar, $\mathbf{b}$ body size (cephalothorax width) per day after birth. Females have two to four developmental instars more than males, but also grow faster. Lines represent the best fit of a Gamma GLMM and shaded areas represent the $95 \%$ confidence interval

\section{Results}

\section{Growth trajectories}

Female and male M. celer growth trajectories differed in both length and shape (Figure 1). Females matured in eight $(\mathrm{N}=14)$, nine $(\mathrm{N}=18)$ or ten instars $(\mathrm{N}$ $=11)$, while males matured in six $(\mathrm{N}=16)$ or seven instars $(\mathrm{N}=18)$. Females reached maturity in an average of 273.7 days $(\min =102$, $\max =394)$, while males took on an average 204 days $(\min =109, \max =345)$. Females and males differed significantly in the size (cephalothorax width) from the fifth instar onward (Table 2, non-overlapping confidence intervals in Figure 1), as well as in the relationship between size and age in days (Table 3; Figure 2).
Table 2. Gamma GLMM testing the relation between Mecaphesa celer size (cephalothorax width) at each developmental instar and sex

\begin{tabular}{lclrr} 
& Estimate & St. error & \multicolumn{1}{c}{$t$} & $p$ \\
Intercept & -0.57 & 0.03 & -21.67 & $<0.001$ \\
Instar & 0.16 & 0.003 & 61.25 & $<0.001$ \\
Sex (M vs. F) & 0.10 & 0.04 & 2.68 & 0.007 \\
Instar * sex & -0.03 & 0.005 & -6.03 & $<0.001$
\end{tabular}

$N=304$, deviance $=-526.2$, random effect variance: spiderling ID: family $=0.002$, st. dev. $=0.05$, family $=0.0003$, st. dev. $=0.01$; likelihood ratio test: $x^{2}=848.8, d f=3, p<0.001$

Table 3. Gamma GLMM testing the relation between Mecaphesa celer size (cephalothorax width), age in days and sex

$\begin{array}{lllrc} & \text { Estimate } & \text { St. error } & t & p \\ \text { Intercept } & -0.45 & 0.05 & -8.99 & <0.001 \\ \text { Age (days) } & 0.005 & 0.0001 & 35.57 & <0.001 \\ \text { Sex (F vs. M) } & 0.13 & 0.07 & 1.95 & 0.05 \\ \text { Age * sex } & 0.002 & 0.0002 & -6.40 & <0.001\end{array}$

$N=304$, deviance $=-216.19$; random effect variance: spiderling ID: family $=0.01$, st. dev. $=0.1$, family $=0.001$, st. dev. $=$ 0.04; Likelihood ratio test: $\chi^{2}=539.32, d f=3, p<0.001$

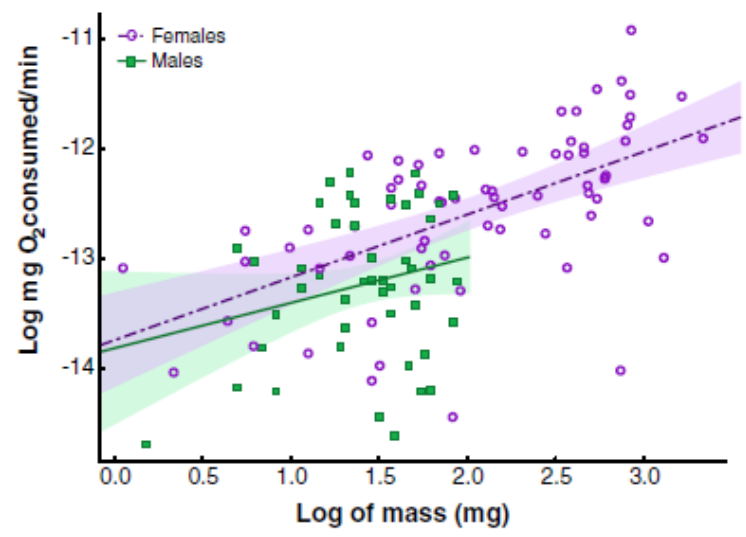

Figure 2. Resting metabolic rate scaling with mass of both female and male Mecaphesa celer at different points of their ontogeny. Lines represent the best fit of a linear model and shaded areas represent the $95 \%$ confidence interval

Energetic demand quantification: metabolic rate measurements

Mecaphesa celer's resting metabolic rate scaled with mass with a slope of 0.57 . Contrary to our predictions, neither the slope nor the intercept of the massresting metabolic rate relationship differed between females and males (Likelihood ratio test of models with and without the variable "sex": $X^{2}=1.33, p=0.51$, Table 4, Figure 3). 
Table 4. LMM testing the effect of log of mass (mg), sex, and their interaction on the resting metabolic rate $\left(\mathrm{mg} \mathrm{O}_{2}\right.$ consumed/min) of Mecaphesa celer spiders along their ontogeny

$\begin{array}{lcccc} & \text { Estimate } & \text { St. error } & t & p \\ \text { Intercept } & -13.72 & 0.21 & -64.22 & <0.001 \\ \text { Sex } & -0.08 & 0.41 & -0.19 & 0.85 \\ \text { Log mass } & 0.57 & 0.10 & 5.79 & <0.001 \\ \text { Sex }{ }^{*} \log \text { mass } & -0.16 & 0.26 & -0.61 & 0.55\end{array}$
Spiderling families were used as random effect. $\chi^{2}=44.85, d f$ $=3, p=9.98 \mathrm{e}-10$

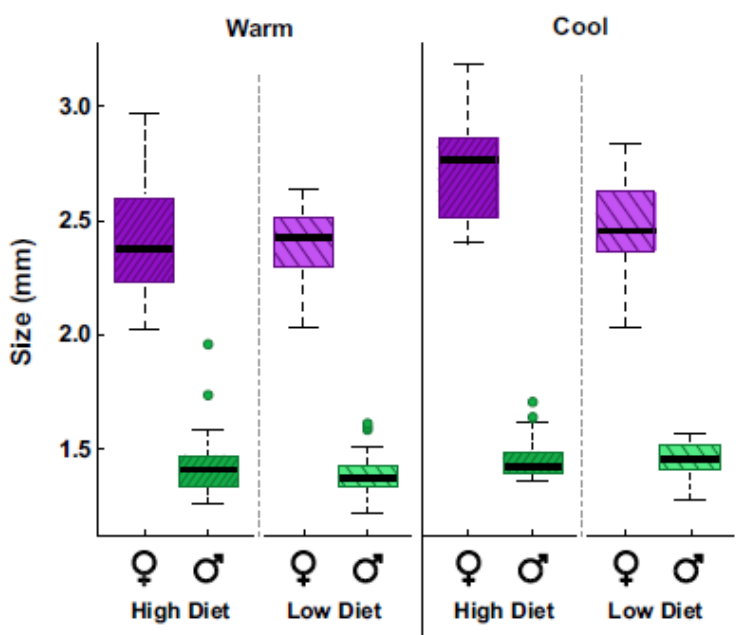

Figure 3. Size (cephalothorax width) of adult female and male Mecaphesa celer in two diet and temperature treatments. Boxes correspond to first quartile, median and third quartile, whiskers correspond to the range (not including outliers, which are represented by points). Females are represented by purple and males by green, and the boxes' pattern matches the diet treatment (narrow stripes for high diet, wide stripes for low diet) (color figure online)

Environmental effects on SSD: diet and temperature manipulation

Diet, temperature, and their interaction affected M. celer size (Table 5). Individuals in the High dietCool (HC) treatment achieved the largest sizes of all treatments, while individuals in the LW treatment achieved the smallest sizes (Table 5; Figure 3). Females in the $\mathrm{HC}$ diet were on average $12 \%$ larger than females in the LW treatment, while HW males were just $6 \%$ larger than LW males. Females were larger than males, with no overlap in size distribution, in all treatments (Figure 3). Female size had a larger variance than male size both within and between treatments (Figure 3).
Table 5. Linear model testing the effect of diet, temperature, sex, and their interaction on the size (cephalothorax width) of adult Mecaphesa celer spiders

$\begin{array}{lrlrr} & \text { Estimate } & \text { St. error } & t & p \\ \text { Intercept } & 2.71 & 0.04 & 66.17 & <0.001 \\ \text { Sex (M vs. F) } & -1.25 & 0.05 & -23.49 & <0.001 \\ \text { Diet (high vs. low) } & -0.24 & 0.05 & -4.63 & <0.001 \\ \text { Temperature (warm vs. } & -0.30 & 0.05 & -6.39 & <0.001 \\ \text { cool) } & & & & \\ \text { Sex * diet } & 0.23 & 0.07 & 3.23 & 0.001 \\ \text { Sex * temperature } & 0.28 & 0.06 & 4.29 & <0.001 \\ \text { Diet * temperature } & 0.24 & 0.06 & 3.65 & <0.001 \\ \text { Sex * diet * temperature }-0.27 & 0.09 & -3.02 & 0.003 \\ \text { Multiple } R \text {-squared: } 0.91, R \text {-squared: } 0.91, F=342.2, d f=226, \\ p \leq 0.001\end{array}$

\section{Discussion}

Understanding the ontogenetic, energetic, and environmental determinants of SSD is paramount to understanding the ecology and evolution of sexually dimorphic species. Such an understanding is, however, still currently lacking. Using an integrative approach, here we show that the shape of females' growth curve is the main developmental mechanism of SSD in this species. Surprisingly, Mecaphesa celer females' faster and longer growth seems unrelated to either sex' mass-specific resting metabolic rate. Also, the energy available to each sex (diet treatments) had only a modest effect on the size obtained by both females and males at adulthood, and was influenced through an interactive effect with temperature. Both temperature and diet had a stronger effect on adult female size than on male size.

\section{Growth trajectories}

Females do not grow faster than males throughout their entire ontogeny, but rather grow faster only from their fifth instar on. The non-linear shape of the growth trajectory at the basis of the observed differences is, therefore, only visible after the appearance of the external secondary sexual characters of these animals. The simultaneous appearance of secondary sexual characters and sexual size dimorphism suggests an endocrine basis to differences in growth rate observed between the sexes from their fifth instar onward (see Cox et al. 2005). This is consistent with the results of Trabalon and Blais (2012) showing an increase in the arthropod hormone ecdysteroid in males, one instar prior to adulthood, concomitantly with a differentiation of females' and males' growth rates and the appearance of secondary sexual traits.

The role of the functional form of the growth trajectory cannot be observed if growth rate is determined 
simply as the static relationship between size at adulthood and development time. Erroneously assuming that SSD is caused by linear differences in growth rate or differences in development time makes it impossible to correctly identify the target of selection: growth rate, developmental time, or shape of the growth curve (Tammaru and Esperk 2007; Tammaru et al. 2010; Vendl et al. 2018). Our results, thus, stress the need for long-term experiments to get a complete picture of the processes that lead to SSD.

\section{Energetics of growth}

Most models of ontogenetic growth predict a relationship between growth rate, the amount of energy ingested, and the cost of maintaining an organism's existing tissues (e.g. West et al. 2001; Ricklefs 2003; Moses et al. 2008; Hou et al. 2008; DeLong 2012). As such, it is surprising that females and males raised in identical conditions reach drastically different sizes despite having virtually identical resting metabolic rates throughout their ontogeny. Females are nonetheless growing faster than males, and, as such, must obtain the fuel for this growth from somewhere, either through reduced energetic expenditure, or through increased energetic intake (Dmitriew 2011).

\section{Differences in energetic expenditure}

Sex-specific levels of energetic expenditure could be related to each sex's active metabolic rate (i.e. metabolic rates reached during activity) rather than resting metabolic rate (Gade 2002; Downs et al. 2016). Differences between active and resting metabolic rates between females and males have not been observed in spiders (Shillington and Peterson 2002), but this hypothesis should nonetheless be tested.

Differences in behavior also may result in sexspecific energetic expenditures. In multiple sexually size dimorphic species, females and males differ in their activity levels and overall life history (Vollrath and Parker 1992; Vollrath 1998; Beck et al. 2007; Tammaru et al. 2010; Rohner et al. 2017) - e.g., the larger sex is often less mobile than the smaller sex (GonzálezSolís et al. 2000; Mikolajewski et al. 2005; Dodson et al. 2015; but see Rennie et al. 2008). In spiders, adult females of the most extremely SSD species, including $M$. celer, are highly specialized sit-and-wait predators, while males typically spend their adult instar roaming in search of females (Walker and Rypstra 2001, 2002; Foellmer and Moya-Larano 2007; Dodson et al. 2015). As a consequence, females could fuel their faster growth simply by being less active than males, allowing them to allocate more of their available energy to growth. To test this hypothesis, we would have to assess if differences in activity levels between females and males extend from early instars to adulthood.
Most studies on life history divergence between the sexes focus solely on adults, unfortunately. Nonetheless, this behavioral difference is a likely explanation for our observed differences in growth trajectory with no underlying difference in female and male metabolic rates, and, upon being corroborated, could be considered a novel mechanism of sexual size dimorphism. From an evolutionary standpoint, the increased activity of males may lead to an increased mortality risk, which would select for smaller, inconspicuous, and rapidly maturing males (Blanckenhorn 2000).

\section{Differences in energetic intake}

Alternatively, or in addition to differences in activity levels, SSD may be proximately caused by differences in the energy assimilated by each sex. In other words, the larger sex may forage more efficiently throughout their development than the smaller sex (Shine 1989; Rohner et al. 2018). Foraging is, however, in and of itself an energetically costly process that scales with predator size (Tenhumberg et al. 2000; Carbone et al. 2007). Smaller organisms reach satiation faster and may, therefore, minimize their foraging effort regardless of how much food is available in the wild. Such a reduction in foraging effort allows for more time and energy to be spent in reproductive activities (Blanckenhorn et al. 1995; Blanckenhorn and Viele 1999; Blanckenhorn 2005). In a sex for which there are no benefits associated with being large (i.e. male M. celer, see Chelini and Hebets 2016), optimal size might, therefore, be selected by the temporal and energetic benefits of being small, and might remain relatively fixed regardless of the foraging conditions under which males grow (Shine 1989; Blanckenhorn 2000). Females, on the other hand, are likely to be under selection for larger sizes and maximized food consumption due to the fecundity benefits associated with size (Richard Shine 1988; Honěk and Honek 1993; Preziosi et al. 1996). Indeed, in multiple orders of insects, female growth is known to be more sensitive to environmental conditions than male growth (Teder and Tammaru 2005).

Our results fit this pattern, as diet had a stronger effect on female size than on male size. The fact that all treatments have similar degrees of sexual size dimorphism demonstrates that differential food access is not the limiting factor of male size, but indicates that differences in actual energetic assimilation underlie the growth rates of female and male $M$. celer. In the wild, female sit-and-wait foraging strategy likely minimizes the energetic cost of foraging (Norberg 1977; Anderson and Karasov 1981). Moreover, females are likely to have access to larger and more energetically rewarding prey items than males, as a positive feedback generated from obtaining larger size (see Holtby and Healey 1990; González-Solís et al. 2000; Brose et al. 2006; Brose 
2010, for examples, on size-dependent sex-specific foraging strategies in mammals and fish). It is, therefore, possible that extreme degrees of SSD may be proximately caused by differences in the foraging efficiency of females and males throughout their development, with the larger sex presenting a foraging behavior that combines higher energetic assimilation through access to larger prey items and lower energetic demands due to lower activity.

\section{Environmental effects on SSD}

Individuals in the High diet-Cool treatment reached the largest sizes among our four treatments. The negative effect of warm temperatures on M. celer's body size is in accordance with the temperature-size rule, which predicts that ectotherms will develop for longer and reach larger sizes at lower temperatures (Atkinson 1994; Forster and Hirst 2012). Metabolic rates are known to increase with temperature (Gillooly et al. 2001; Schmalhofer 2011), thus individuals from the Cool treatment must have lower metabolic rates throughout their ontogeny than individuals from the Warm treatments. A lower metabolic rate would, in turn, allow these Cool individuals to invest more of their energetic supply toward growth than those of Warm treatments, resulting in larger adults. We must, however, consider the fact that, due to factors outside of our control, the effect of cooler temperatures in our treatments is confounded with the effect of fluctuating temperatures. Our Cool treatments were consistently cooler than the Warm treatments, and differed on average by $8^{\circ} \mathrm{C}$, a major difference bound to have effects on the development of $M$. celer. Nonetheless, our experiment demonstrates clearly that the environment has an effect on the adult size of both males and females, and consequently that the degree of SSD is dependent on environmental conditions, corroborating our hypothesis. Growth is known to be plastic in many arthropods, varying according to temperature, diet, days between feeding events, photoperiod, among others (Teder and Tammaru 2005; Stillwell et al. 2010; Dmitriew 2011; Hirst et al. 2015). Other animals such as salmonids have been shown to regulate their metabolic rates according to food availability, allowing individuals to maximize their growth even in conditions where food was limited (Auer et al. 2015). In our results, the interactive effect between diet and temperature on body size suggests that the balance between energy acquisition and energy expenditure that leads to SSD greatly depends on environmental conditions. The fact that the environment had a stronger effect in females than males fits with what is known in other arthropods, as the larger sex is known to be more plastic in multiple orders of holometabolous insects (Teder and Tammaru 2005; Rohner et al. 2018). Interactive effects of sex-specific plasticity, diet, and temperature may contribute to intraspecific variation in magnitude of SSD observed in many animal species distributed across a wide geographic and environmental range.

\section{Conclusions}

Our results highlight the importance of analyzing the entire ontogeny of a species to fully understand the developmental basis of SSD. We revealed that differences in growth rate are not constant throughout $M$. celer's ontogeny, nor linear, and suggest an endocrine basis to the observed differences. Also, differences in resting metabolic rates do not underlie SSD in this species, suggesting that females achieve a higher growth rate through a combination of increased energy assimilation and decreased energy expenditure compatible with a sit-and-wait foraging strategy, which represents a compromise between the classical competing models of SSD development: higher energy acquisition or lower energy expenditure. Our results further suggest the possibility of a new mechanism of SSD driven by differences in energy expenditure through behavior. As we gain a better understanding of the growth trajectories leading to SSD, we must take into account the ontogenetic differences between the sexes and develop new theoretical models predicting the relation between metabolism and growth to fully understand the evolution of SSD. As for empirical studies, our research shows that crab spiders are an excellent subject for studies on the development of SSD and growth physiology in arthropods.

Acknowledgements D. Izaguirre, D. Myers, M. Potts, A. Schmidt, R. Pettit, R. N'Guyen, A. Lehman, and K. Clay helped with spider maintenance. W. Wagner, D. Ledger, J. Stevens, and J.P. Gibert provided us feedback on this manuscript.

Author contribution statement MCC, JPD, and EH conceived the ideas and designed methodology, MCC collected and analyzed the data, MCC wrote the first version of the manuscript, and all authors contributed to subsequent versions.

\section{Compliance with ethical standards}

Conflict of interest The authors have no conflict of interest to declare.

Ethical approval All applicable institutional and/or national guidelines for the care and use of animals were followed.

\section{References}

Anderson RA, Karasov WH (1981) Contrasts in energy intake and expenditure in sit-and-wait and widely foraging lizards. Oecologia 49:67-72. https://doi.org/10.1007/BF00376899

Atkinson D (1994) Temperature and Organism Size: A Biological Law for Ectotherms? Advances in ecological research pp 158. Elsevier. 
Auer SK, Salin K, Rudolf AM et al (2015) Flexibility in metabolic rate confers a growth advantage under changing food availability. J Anim Ecol 84:1405-1411. https:// doi.org/10.1111/1365-2656.12384

Badyaev AV (2002a) Growing apart: an ontogenetic perspective on the evolution of sexual size dimorphism. Trends Ecol Evol 17:369-378. https://doi.org/10.1016/S01695347(02)02569-7

Badyaev AV (2002b) Male and female growth in sexually dimorphic species: harmony, conflict, or both? Comments Theor Biol 7:11-33. https:// doi.org/10.1080/08948550212973

Bates D, Maechler M, Bolker B, Walker S (2015) Fitting linear mixed-effects models using Ime4. J Stat Soft 67(1):1-48

Beck CA, Iverson SJ, Bowen WD, Blanchard W (2007) Sex differences in grey seal diet reflect seasonal variation in foraging behaviour and reproductive expenditure: evidence from quantitative fatty acid signature analysis. $J$ Anim Ecol 76:490-502. https://doi.org/10.1111/j.13652656.2007.01215.x

Blanckenhorn WU (2000) The evolution of body size: what keeps organisms small? Q Rev Biol 75:385-407

Blanckenhorn WU (2005) Behavioral causes and consequences of sexual size dimorphism. Ethology 111:977-1016. https://doi.org/10.1111/j.1439-0310.2005.01147.x

Blanckenhorn WU, Viele SNT (1999) Foraging in yellow dung flies: testing for a small-male time budget advantage. Ecol Entomol 24:1-6. https://doi.org/10.1046/j.13652311.1999.00171.x

Blanckenhorn WU, Preziosi RF, Fairbairn DJ (1995) Time and energy constraints and the evolution of sexual size dimorphism - to eat or to mate? Evol Ecol 9:369-381. https:// doi.org/10.1007/BF01237760

Blanckenhorn WU, Dixon AFG, Fairbairn DJ et al (2007) Proximate causes of Rensch's rule: does sexual size dimorphism in arthropods result from sex differences in development time? Am Nat 169:245-257. https://doi.org/10.1086/510597

Bolker BM, Brooks ME, Clark CJ et al (2009) Generalized linear mixed models: a practical guide for ecology and evolution. Trends Ecol Evol 24:127-135. https:// doi.org/10.1016/j.tree.2008.10.008

Brose U (2010) Body-mass constraints on foraging behaviour determine population and food-web dynamics. Funct Ecol 24:28-34. https://doi.org/10.1111/j.13652435.2009.01618.x

Brose U, Jonsson T, Berlow EL et al (2006) Consumer-resource body-size relationships in natural food webs. Ecology 87:2411-2417

Budrienė A, Budrys E, Nevronytė Ž (2013) Sexual size dimorphism in the ontogeny of the solitary predatory wasp Symmorphus allobrogus (Hymenoptera: Vespidae). C R Biol 336:57-64.

https://doi.org/10.1016/j.crvi.2013.03.001

Carbone C, Teacher A, Rowcliffe JM (2007) The costs of carnivory. PLoS Biol 5:e22. https://doi.org/10.1371/journal.pbio. 0050022

Chelini M-C, Hebets EA (2016) Absence of mate choice and postcopulatory benefits in a species with extreme sexual size dimorphism. Ethology 122:95-104.

https://doi.org/10.1111/eth.12449

Chelini M-C, Hebets E (2017) Field evidence challenges the often-presumed relationship between early male maturation and female-biased sexual size dimorphism. Ecol Evol 7:9592-9601
Chou C-C, Iwasa Y, Nakazawa T (2016) Incorporating an ontogenetic perspective into evolutionary theory of sexual size dimorphism. Evolution 70:369-384. https:/ / doi.org/10.1111/evo.12857

Cox RM, Calsbeek R (2009) Sexually antagonistic selection, sexual dimorphism, and the resolution of intralocus sexual conflict. Am Nat 173:176-187. https://doi.org/10.1086/595841

Cox RM, Skelly SL, Leo A, John-Alder HB (2005) Testosterone regulates sexually dimorphic coloration in the Eastern Fence Lizard, Sceloporus undulatus. Copeia 2005:597608. https:// doi.org/10.1643/CP-04-313R

DeLong JP (2012) Experimental demonstration of a 'ratesize' trade-off governing body size optimization. Evol Ecol Res 14:343-352

DeLong JP, Gilbert B, Shurin JB et al (2015) The body size dependence of trophic cascades. Am Nat 185:354-366. https:// doi.org/10.1086/679735

Dmitriew CM (2011) The evolution of growth trajectories: what limits growth rate? Biol Rev 86:97-116. https://doi.org/10.1111/j.1469185X.2010.00136.x

Dodson GN, Beck MW (1993) Pre-copulatory guarding of penultimate females by male crab spiders, Misumenoides formosipes. Anim Behav 46:951-959.

https://doi.org/10.1006/anbe.1993.1276

Dodson GN, Anderson AG, Stellwag LM (2015) Movement, sex ratio, and population density in a dwarf male spider species, Misumenoides formosipes (Araneae: Thomisidae). J Arachnol 43:388-393. https://doi.org/10.1636/arac-43-03388-393

Downs CJ, Brown JL, Wone BWM et al (2016) Speeding up growth: selection for mass-independent maximal metabolic rate alters growth rates. Am Nat 187:295-307. https:/ / doi.org/10.1086/684837

Fairbairn DJ (1997) Allometry for sexual size dimorphism: pattern and process in the coevolution of body size in males and females. Annu Rev Ecol Syst 2:659-687

Foelix RF (2011) Biology of Spiders, 3rd ed. Oxford University Press.

Foellmer MW, Moya-Larano J (2007) Sexual size dimorphism in spiders: patterns and processes. In: Sex, size and render roles: evolutionary studies of sexual size dimorphism. $O x$ ford Biol, p 266

Forster J, Hirst AG (2012) The temperature-size rule emerges from ontogenetic differences between growth and development rates: Ontogenetic differences between growth and development

rates. Funct Ecol 26:483-492. https:// doi.org/10.1111/j.13652435.2011.01958.x

Fuselier L, Decker P, Lunski J et al (2007) Sex differences and size at emergence are not linked to biased sex ratios in the Common Green Darner, Anax junius (Odonata: Aeshnidae). J Freshw Ecol 22:107-117.

https:// doi.org/10.1080/02705060.2007.9664151

Gade G (2002) Sexual dimorphism in the pyrgomorphid grasshopper Phymateus morbillosus: from wing morphometry and flight behaviour to flight physiology and endocrinology. Physiol Entomol 27:51-57.

https://doi.org/10.1046/j.1365-3032.2002.00268.x

Garel M, Solberg EJ, Sæther B-E et al (2006) The length of growing season and adult sex ratio affect sexual size dimorphism in moose. Ecology 87:745-758

Gillooly JF, Brown JH, West GB et al (2001) Effects of size and temperature on metabolic rate. Science 293:2248-2251. https://doi.org/10.1126/science.1061967 
Gillooly JF, Allen AP, West GB, Brown JH (2005) The rate of DNA evolution: effects of body size and temperature on the molecular clock. Proc Natl Acad Sci 102:140-145. https:// doi.org/10.1073/pnas.0407735101

González-Solís J, Croxall JP, Wood AG (2000) Sexual dimorphism and sexual segregation in foraging strategies of northern giant petrels, Macronectes halli, during incubation. Oikos 90:390-398. https:// doi.org/10.1034/j.16000706.2000.900220.x

Hirst AG, Horne CR, Atkinson D (2015) Equal temperaturesize responses of the sexes are widespread within arthropod species. Proc R Soc B Biol Sci 282:20152475. https://doi.org/10.1098/rspb.2015.2475

Holtby LB, Healey MC (1990) Sex-specific life history tactics and risk-taking in Coho Salmon. Ecology 71:678-690. https://doi.org/10.2307/1940322

Honěk A, Honek A (1993) Intraspecific variation in body size and fecundity in insects: a general relationship. Oikos 66:483. https://doi.org/10.2307/3544943

Hormiga G, Scharff N, Coddington JA (2000) The phylogenetic basis of sexual size dimorphism in orb-weaving spiders (Araneae, Orbiculariae). Syst Biol 49:435-462. https:// doi.org/10.1080/10635159950127330

Hou C, Zuo W, Moses ME et al (2008) Energy uptake and allocation during ontogeny. Science 322:736-739. https:// doi.org/10.1126/ science.1162302

Isaac JL (2005) Potential causes and life-history consequences of sexual size dimorphism in mammals. Mammal Rev 35:101-115. https://doi.org/10.1111/j.13652907.2005.00045.x

Legrand RS, Morse DH (2000) Factors driving extreme sexual size dimorphism of a sit-and-wait predator under low density. Biol J Linn Soc 71:643-664. https://doi.org/10.1111/j.1095-8312.2000.tb01283.x

Leigh SR, Shea BT (1996) Ontogeny of body size variation in African apes. Am J Phys Anthropol 99:43-65. https://doi.org/10.1002/(SICI)10968644(199601)99:1\%3c43:AID-AJPA3\%3e3.0.CO;2-0

Mikolajewski DJ, Brodin T, Johansson F, Joop G (2005) Phenotypicplasticity in gender specific life-history: effects of food availability and predation. Oikos 110:91-100. https://doi.org/10.1111/j.0030-1299.2005.13766.x

Morse DH (2013) Reproductive output of a female crab spider: the impacts of mating failure, natural enemies, and resource availability. Entomol Exp Appl 146:141-148. https:// doi.org/10.1111/j.1570-7458.2012.01301.x

Moses ME, Hou C, Woodruff WH et al (2008) Revisiting a model of ontogenetic growth: estimating model parameters from theory and data. Am Nat 171:632-645. https:// doi.org/10.1086/587073

Muniappan R, Chada HL (1970) Biology of the crab spider, Misumenops celer. Ann Entomol Soc Am 63:1718-1722. https://doi.org/10.1093/aesa/63.6.1718

Norberg RA (1977) An ecological theory on foraging time and energetics and choice of optimal food-searching method. J Anim Ecol 46:511. https:/ / doi.org/10.2307/3827

O'Mara MT, Gordon AD, Catlett KK et al (2012) Growth and the development of sexual size dimorphism in lorises and galagos. Am J Phys Anthropol 147:11-20. https://doi.org/10.1002/ajpa.21600

Ono KA, Boness DJ (1996) Sexual dimorphism in sea lion pups: differential maternal investment, or sex-specific differences in energy allocation? Behav Ecol Sociobiol 38:31-41

Prenter J, Montgomery WI, Elwood RW (1995) Multivariate morphometrics and sexual dimorphism in the orb-web spider Metellina segmentata (Clerck, 1757) (Araneae, Metidae). Biol J Linn Soc 55:345-354.

https:// doi.org/10.1111/j.1095-8312.1995.tb01070.x

Preziosi RF, Fairbairn DJ (2000) Lifetime selection on adult body size and components of body size in a water strider: opposing selection and maintenance of sexual size dimorphism. Evolution 54:558-

566. https:// doi.org/10.1111/j.0014-3820.2000.tb00058.x

Preziosi RF, Fairbairn DJ, Roff DA, Brennan JM (1996) Body size and fecundity in the water strider Aquarius remigis: a test of Darwin's fecundity advantage hypothesis. Oecologia 108:424-431

R Core Team (2014) R: A language and environment for statistical computing. R Foundation for Statistical Computing, Vienna, Austria. http://www.R-project.org/

Rennie MD, Purchase CF, Lester N et al (2008) Lazy males? Bioenergetic

differences in energy acquisition and metabolism help to explain sexual size dimorphism in percids. J Anim Ecol 77: 916-926. https:// doi.org/10.1111/j.1365-2656.2008.01412.x

Ricklefs RE (2003) Is rate of ontogenetic growth constrained by resource supply or tissue growth potential? A comment on West et al's model. Funct Ecol 17:384-393. https://doi.org/10.1046/j.1365-2435.2003.00745.x

Riede JO, Brose U, Ebenman B et al (2011) Stepping in Elton's footprints: a general scaling model for body masses and trophic levels across ecosystems: stepping in Elton's footprints. Ecol Lett 14:169-178. https://doi.org/10.1111/j.1461-0248.2010.01568.x

Rohner PT, Blanckenhorn WU, Schäfer MA (2017) Critical weight mediates sex-specific body size plasticity and sexual dimorphism in the yellow dung fly Scathophaga stercoraria (Diptera: Scathophagidae). Evol Dev 19:147-156. https://doi.org/10.1111/ede.12223

Rohner PT, Teder T, Esperk T et al (2018) The evolution of male-biased sexual size dimorphism is associated with increased body size plasticity in males. Funct Ecol 32:581591. https:// doi.org/10.1111/1365-2435.13004

Savage VM, Gillooly JF, Brown JH et al (2004) Effects of body size and temperature on population growth. Am Nat 163:429-441. https://doi.org/10.1086/381872

Scharff N, Coddington JA (1997) A phylogenetic analysis of the orb-weaving spider family Araneidae (Arachnida, Araneae). Zool J Linn Soc 120:355-434. https:// doi.org/10.1111/j.1096-3642.1997.tb01281.x

Schmalhofer VR (2011) Impacts of temperature, hunger and reproductive condition on metabolic rates of flower-dwelling crab spiders (Araneae: Thomisidae). J Arachnol 39:4152. https:// doi.org/10.1636/Hi09-103.1

Shillington C, Peterson CC (2002) Energetics of male and female tarantulas. J Exp Biol 205:2909-2914

Shine Richard (1988) The evolution of large body size in females: a critique of Darwin's "Fecundity Advantage" model. Am Nat 131:124-131

Shine R (1989) Ecological causes for the evolution of sexual dimorphism: a review of the evidence. $Q$ Rev Biol 64:419-461

Shine R (1994) Sexual size dimorphism in snakes revisited. Copeia 1994:326. https:/ / doi.org/10.2307/1446982

Smith RJ, Leigh SR (1998) Sexual dimorphism in primate neonatal body mass. J Hum Evol 34:173-201.

https://doi.org/10.1006/jhev.1997.0190

Stearns SC (1976) Life-history tactics: a review of the ideas. $Q$ RevBiol 51:3-47. https:/ / doi.org/10.1086/409052

Stearns SC (1989) Trade-offs in life-history evolution. Funct Ecol 3:259. https:// doi.org/10.2307/2389364 
Chelini, Delong, and Hebets in Oecologia (2019) 191: 61-71.

Stillwell RC, Davidowitz G (2010) Sex differences in phenotypic plasticity of a mechanism that controls body size: implications for sexual size dimorphism. Proc R Soc B Biol Sci 277:3819-3826. https://doi.org/10.1098/rspb.2010.0895

Stillwell RC, Blanckenhorn WU, Teder T et al (2010) Sex differences in phenotypic plasticity affect variation in sexual size dimorphism in insects: from physiology to evolution. Annu Rev Entomol 55:227-245. https://doi.org/10.1146/annurev-ento-112408-085500

Tammaru T, Esperk T (2007) Growth allometry of immature insects: larvae do not grow exponentially. Funct Ecol 21:1099-1105. https://doi.org/10.1111/j.13652435.2007.01319.x

Tammaru T, Esperk T, Ivanov V, Teder T (2010) Proximate sources of sexual size dimorphism in insects: locating constraints on larval growth schedules. Evol Ecol 24:161-175. https:// doi.org/10.1007/s10682-009-9297-1

Teder T (2014) Sexual size dimorphism requires a corresponding sex difference in development time: a meta-analysis in insects. Funct Ecol 28:479-486. https://doi.org/10.1111/1365-2435.12172

Teder T, Tammaru T (2005) Sexual size dimorphism within species increases with body size in insects. Oikos 108:321334. https:// doi.org/10.1111/j.0030-1299.2005.13609.x

Tenhumberg B, Tyre AJ, Roitberg B (2000) Stochastic variation in food availability influences weight and age at maturity. J Theor Biol 202:257-272. https://doi.org/10.1006/jtbi.1999.1049

Trabalon M, Blais C (2012) Juvenile development, ecdysteroids and hemolymph level of metabolites in the spider Brachypelma albopilosum (Theraphosidae). J Exp Zool Part
Ecol Genet Physiol 317:236-247. https://doi.org/10.1002/jez.1717

Vendl T, Kratochvíl L, Šípek P (2016) Ontogeny of sexual size dimorphism in the hornless rose chafer Pachnoda marginata (Coleoptera: Scarabaeidae: Cetoniinae). Zoology 119:481-488. https:// doi.org/10.1016/j.zool.2016.07.002

Vendl T, Šípek P, Kouklík O, Kratochvíl L (2018) Hidden complexity in the ontogeny of sexual size dimorphism in male-larger beetles. Sci Rep 8:5871.

https://doi.org/10.1038/s41598-018-24047-1

Vollrath F (1998) Dwarf males. Trends Ecol Evol 13:159-163. https:// doi.org/10.1016/S0169-5347(97)01283-4

Vollrath F, Parker GA (1992) Sexual dimorphism and distorted sex ratios in spiders. Nature 360:156-159. https:// doi.org/10.1038/360156a0

Walker SE, Rypstra AL (2001) Sexual dimorphism in functional response and trophic morphology in Rabidosa rabida (Araneae: Lycosidae). Am Midl Nat 146:161-170. https:// doi.org/10.1674/00030031(2001)146\%5b0161:sdifra \%5d2.0.co;2

Walker SE, Rypstra AL (2002) Sexual dimorphism in trophic morphology and feeding behavior of wolf spiders (Araneae: Lycosidae) as a result of differences in reproductive roles. Can J Zool 80:679-688. https:// doi.org/10.1139/z02-037

Weatherhead PJ, Teather KL (1994) Sexual size dimorphism and egg-size allometry in birds. Evolution 48:671-678. https://doi.org/10.1111/j.1558-5646.1994.tb01352.x

West GB, Brown JH, Enquist BJ (2001) A general model for ontogenetic growth. Nature 413:628-631. https:// doi.org/10.1038/35098076 